Kompass

Pneumologie

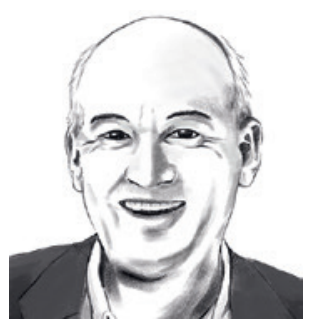

Harald Walach

Poznan/Berlin

Polen/Deutschland

Yuval Noah Harari hat die These in die Welt gesetzt, dass das Zukunftsprojekt der Menschheit die Unsterblichkeit sei [1]. Sie sei die logische Konsequenz dessen, was die Medizin seit geraumer Zeit macht: Leben nicht nur zu retten, sondern möglichst das Sterben zu verhindern oder hinauszuzögern, so dass man bald von einer funktionellen Unsterblichkeit reden könne. Nicht, dass man gar nicht mehr sterben kann. Ein Unfall, ein akuter Herzinfarkt kann auch weiterhin den Tod bedeuten. Aber die Entwicklung ginge unaufhaltsam dahin, dass man durch mechanische oder physiologisch in Petrischalen gewachsene Ersatzteile aus Stammzellen oder anderen Zellen neue funktionsfähige Organe erzeugen und damit das Leben verlängern würde können, solange, bis die Verschiebung des Todes bis weit in die Zukunft hinein nicht nur theoretisch denkbar, sondern auch praktisch machbar wird. Damit wir uns recht verstehen, ich rede nicht von der Ausschöpfung der physiologisch offenbar möglichen Lebensdauer eines gesunden Menschen unter optimalen Bedingungen von 120-130 Jahren. Wir reden von einer faktischen Abschaffung des Todes. Führende Vertreter des Transhumanismus wie Nick Bostrom vom Future of Humanity Institute in Oxford [2] sind der Meinung, dass es technisch in naher Zukunft möglich sein werde, heute noch unheilbare Krankheiten Krebs, Alzheimer, derlei Sachen - zu kurieren. Darum haben sie sich auf ein kryomedizinisches Unternehmen abonniert, das ihren Körper einfrieren wird, wenn sie so unheilbar krank sind, dass der Tod vor der Tür steht. So-

\section{Literatur}

1 Harari YN: Homo Deus. A Brief History of Tomorrow. London, Vintage, 2017.

2 Bostrom N: Superintelligence. Paths, Dangers, Strategies. Oxford, Oxford University Press, 2014.

\title{
Transhumanismus: Welchen Menschen wollen wir?
}

bald diese Krankheit heilbar ist, kommt der gut gekühlte Körper aus der Truhe und auf geht's ins neue Leben. Nein, das ist kein Witz, sie meinen das wirklich. Man kann sich dazu stellen, wie man will, aber logisch betrachtet ist dies die Konsequenz der Entwicklung, die die Medizin gegangen ist, seit sie sich konzeptuell dem von Descartes eingeführten und von Virchow kanonisierten Maschinenparadigma verschrieben hat. Und darum ist die Medizin nicht nur Hilfs-, sondern in gewisser Weise Leitwissenschaft unserer Zeit. Denn sie weist den Menschen den Weg in die Zukunft, ja in die Unsterblichkeit. Die Religion, die Philosophie oder spirituelle Traditionen sind allenfalls die Blumenkinder am Rande der wissenschaftlichen Prozession auf dem Weg zur Unsterblichkeit.

Unbemerkt ist die Medizin dabei eine knifflige Liaison mit dem Transhumanismus eingegangen, einer philosophisch-ideologisch-kulturellen Strömung, die davon ausgeht, dass die Entwicklungslinie des Menschen zum Übermenschen, wie Nietzsche ihn skizziert hat, unausweichlich ist. Sie wird als Evolution einer innigen Verbindung von Mensch und Technik geschehen [3] - etwa durch Implantate oder Schnittstellen zu Computern und technische Gadgets. Vielleicht sogar durch die Entwicklung eines Supercomputers, der schlauer ist als alle Menschen und einfach die Welt übernimmt $[4,5]$. Auch wenn es kritische Stimmen gibt $[4,6]$, die medizinisch-technische Entwicklung scheint diesen Analysen recht zu geben. Und zwar nicht, weil es irgendwer plant, sondern einfach, weil die Medizin in diese
Richtung forscht und die Bevölkerung solchen «wissenschaftlichen Fortschritt» enthusiastisch begrüßt.

Daher möchte ich für eine kurze Denkpause plädieren: Ist die funktionale Unsterblichkeit tatsächlich das, was wir wollen, und der Tod um jeden Preis zu verhindern?

Daher möchte ich für eine kurze Denkpause plädieren: Ist die funktionale Unsterblichkeit tatsächlich das, was wir wollen, und der Tod um jeden Preis zu verhindern? Ist nicht, wie manche Denker, spirituelle Traditionen und vielleicht auch die Lebensweisheit nahelegen, der Tod in gewisser Weise die Krönung und das Siegel eines Lebens? Muss nicht das Leben vom Tod her gedacht werden: Wie will ich mein Leben gelebt haben, wenn ich morgen, übermorgen oder in 50 Jahren sterbe? Ist nicht gerade die Endlichkeit das, was allen Entscheidungen, allem Tun und Erlebten Sinn und Würde gibt? Ist nicht der Versuch, den Tod mit technischen Mitteln in die Knie zu zwingen und Gott zu spielen, die ultimative Verirrung des Menschen? Vielleicht sollten wir daher auch Philosophie und Grundlagenreflexion in den Ausbildungskanon der Medizin aufnehmen?

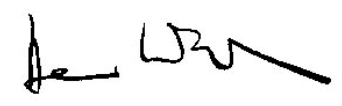

Prof. Dr. Dr. phil. Harald Walach
3 Sorgner SL: Übermensch: Plädoyer für einen Nietzscheanischen Transhumanismus. Basel, Schwabe, 2019.

4 Collins H: Artifictional Intelligence: Against Humanity's Surrender to Computers. Cambridge, Polity Press, 2018.
5 Chalmers DJ: The singularity: A philosophical analysis. J Consciousness Stud. 2010;7:765.

6 Benedikter R: Homo deus? Das Zusammenwachsen von Mensch und Maschine. Analysen \& Argumente. 2017:1-13. 